\title{
The Effect of Background Music on Young People (10-24)' Task Performance
}

\author{
Yuxuan Chen ${ }^{1, *}$
}

\author{
${ }^{1}$ Simon Fraser University, Canada, V5G \\ *Corresponding author. Email: BellaaaahChan@gmail.com
}

\begin{abstract}
Current studies on the effects of background music are controversial and lack consensus. This paper analyzes a large number of previous studies on the relationship between background music and task performance. The purpose of this paper is to explore the best ways for young people to play background music and maximize the positive impact of background music on their learning/cognitive performance. The conclusion was that older students were better suited to playing background music while studying. Appropriate fast-major music with no Lyrics can have the best positive impact on task performance.
\end{abstract}

Keywords: background music, task performance, learning effect, cognitive ability

\section{INTRODUCTION}

With the popularity of electronic products, music has become ubiquitous in daily life, young people especially like to play background music while learning or doing other things. However, researchers still do not have a clear conclusion about the impact of playing background music on the task performance of young people. The current research results on background music are full of controversy and uncertainty, the results of various studies about background music refute each other and lack a unified conclusion [1]. Therefore, the main purpose of this paper is to explore how to use background music to maximize the task performance of young people. This dissertation will examine the following research questions: 1. Which types of background music bring more positive effects? 2. Are there any age or personality differences in the effect of background music on people's task performance? 3 . How to maximize the benefits of background music? In order to address these questions, this paper analyzes and discusses previous relevant studies on background music and makes a systematic summary. This paper will fill the gap about the research of background music and explore whether background music can be applied to the field of education to help improve student's academic achievements.

\section{THREE THEORIES OF HOW BACKGROUND MUSIC INFLUENCING LEARNING}

A large number of studies investigating the relationship between background music and task performance have considered the impact of background music on learners. Three theoretical perspectives can be used to explain the impact on learners [2]. Among them, the Mozart effect and the Arousal-mood-hypothesis explain the positive effect of background music on learning performance; the Seductive detail effect completely refutes the previous two theoretical perspectives and explains the negative effect on learners.

\subsection{Mozart effect}

The Mozart effect is the study of the causal relationship between music and spatial task performance. This study compared the effects of playing Mozart music, playing relaxation tape, and silence on the performance of spatial tasks. The results of this study show that compared to the other two groups, the participants in the Mozart music condition performed best on the spatial task [3]. This means that Mozart music has a positive effect on spatial cognition. However, subsequent research denied the uniqueness of Mozart music. The research results show that the improvement of spatial ability is not caused by Mozart music. The correct explanation for the Mozart 
effect is that liked music will increase personal arousal and mood levels, thereby improving their spatial abilities [4,5]. This is a novel explanation - the Arousal and mood hypothesis.

\subsection{Arousal and mood hypothesis}

The original purpose of the Arousal and mood hypothesis is to explain the Mozart effect. This hypothesis states that music has an influence on the levels of arousal and mood, which then affect the cognitive performance [6]. This hypothesis shows that music does not direct affect the cognitive function. On the contrary, music indirectly affects cognitive ability by changing arousal and mood [7]. Arousal and mood both can be affected by background music and they both play a mediating role in the relationship between background music and cognitive function. Lehmann and Seufert explained these two mediating effects [2].

The tempo of the music determines the increase or decrease of arousal and these details will be discussed in the following sections [6]. More importantly, the level of arousal also needs to be considered. Too low arousal level will lead to insufficient participation in learning, and too high arousal level will lead to distraction. Therefore, a moderate level of arousal can have the best impact on learning [2].

At the same time, music created in different ways will also cause different moods, and moods will affect learning. The mode of the music determines the positive and negative moods, which means the mode of music induces happiness and sadness, and these details will also be discussed in the following sections [6]. The relationship between academic achievement and emotions also shows that positive emotions bring a better learning outcome, and negative emotions bring a worse learning outcome [8]. Husain et al. also point out that the positive moods caused by any stimulus can improve cognitive ability, whether it is music or other stimuli [6]. Although any stimulus that can cause positive moods can improve cognitive function and learning outcomes, music can also be used as a stimulus to bring positive moods. Therefore, music can also play an intermediary role in improving academic achievement and cognitive ability.

He et al. also put forward the importance of the Arousal and mood hypothesis. In their view, the Arousal and mood hypothesis explains why background music brings better cognitive function and learning performance to some people but does not bring benefits to others [9].

\subsection{Seductive detail effect}

The Mozart effect and the Arousal and mood hypothesis both support the statement that background music has a positive effect on task performance. However, the Seductive detail effect is completely opposite to the previous two theoretical perspectives, and it explains why task performance may be negatively affected by background music. The Seductive detail effect is usually associated with cognitive load and attention distraction, which are defined as interesting but irrelevant extra materials in the text [10]. Park et al. used cognitive load theory as a basis to explain how the Seductive detail effect is applied to the statement that "background music has a negative influence on the task performance" [11]. Although the original purpose of Park et al. is to use cognitive load theory to explain the contradictory results of the research on the Seductive detail effect, their theoretical framework (use cognitive load theory to explain the Seductive detail effect) also supports this paper's research on the Seductive detail effect. Park et al. pointed out that learners can only use limited cognitive resources to process different information elements (including intrinsic information elements and extraneous information elements) received by the brain and working memory must process these elements at the same time [11]. Intrinsic information elements refer to the information elements that are actively learned or processed, and extraneous information elements refer to unnecessary cognitive needs. Whether learners want to actively learn necessary learning materials or want to ignore unnecessary cognitive tasks, these information elements will be processed by working memory at the same time. Therefore, learners have to disperse the limited cognitive resources between the intrinsic information elements and the extraneous information elements, which means that the extraneous cognitive load increases and the learning of the intrinsic information elements is reduced.

Seductive detail is defined as extraneous materials which are not related to the learning task, so it can be recognized as an extraneous information element, and it brings extraneous cognitive load. When background music is taken as an example of seductive details and applied to cognitive load theory, such a conclusion can be drawn: background music occupies part of the learners' attention and brings extraneous cognitive load to learners. Therefore, background music can reduce the learners' task performance, which has a negative impact on the learners.

\section{TYPES OF BACKGROUND MUSIC}

When the Arousal and mood hypothesis is introduced, the influences of the tempo and mode of music on arousal and mood are also mentioned. Husain et al. studied the influences of music tempo and mode on spatial task performance, arousal and mood [6]. They divided 36 undergraduate students into four conditional groups with different versions of music: fast-major, fast-minor, slow-major, slow-minor. Participants listened to one of the versions of music and then completed tests on spatial ability, arousal and mood. Their research results show that fast tempo music has a more positive impact on spatial ability than slow tempo music; participants who heard 
major mode perform better on spatial tasks than those who heard minor mode. This is because fast tempo music increases the participants' arousal level, while slow tempo music decreases the participants' arousal level; major mode induced the positive moods of the participants, while minor mode induced the negative mood of the participants [6]. As the author mentioned in the Arousal and mood effect section, arousal and mood can affect cognitive ability. A low level of arousal will reduce the learners' participation in learning, while a high level of arousal will be distracting [2]. Therefore, choosing appropriate fast tempo background music can have a positive impact on learning to the greatest extent. At the same time, positive mood can improve cognitive ability, while negative mood can reduce cognitive ability [8]. Therefore, people should choose the background music which is composed in major mode rather than minor mode when they study.

In addition to the tempo and mode of the background music that will affect the learning results, whether the music contains lyrics is also an important consideration. Perham and Currie focused on comparing the effects of lyrical music and non-lyrical music on the performance of reading comprehension tasks [5]. Participants were 30 undergraduate students, they read four texts in four different sound environments (liked lyrical music, disliked lyrical music, non-lyrical music and quiet) and answered six multiple-choice questions for each text. Research results show that learners perform best under quiet condition and non-lyrical music condition (no significant difference was observed between these two conditions), while the performance of learners under both lyrical music conditions is relatively poor (no significant difference was observed between these two conditions). The research of Perham and Currie mainly shows that non-lyrical music brings better performance in learning tasks than lyrical music [5]. They explained that this result is caused by semantic auditory distraction, that is, learners use limited cognitive resources to process the semantic content of lyrical music, which conflicts with processing task information.

\section{AGE DIFFERENCE \& PERSONALITY DIFFERENCE}

The relationship between background music and learning effect is not only influenced by music type, but also influenced by age difference and personality difference.

Kotsopoulou and Hallam distributed questionnaires to 600 students in three age groups $(12,16-18,20)$, the purpose is to explore whether students of different age groups are aware of the impact of background music on their learning performance and how they use background music in learning [12]. Research results show that more older students (refers to 16-18 and 20 these two age groups) think that background music brings a relaxing effect, and they are also more inclined to be aware of background music distracts them while learning. The important thing is that older students are more willing to do something to reduce the interference caused by background music, such as turning off the music. This indicates that fewer older students will be negatively affected by background music because they are more aware of the negative effects of background music and will try to mitigate these effects.

Even if the author has explored what type of background music can maximize learning efficiency, people cannot guarantee that everyone will get the same impact. Background music that has a positive effect on one person's learning results may has a negative effect on another person. Eysenck believes this is usually caused by the existence of personal differences. Eysenck's theory of personality points out that extraverts perform best in a complex musical environment, while introverts perform best in a quiet environment [13]. Eysenck used cortical arousal theory to explain the difference between extraverts and introverts in the influence of background music. However, his cortical arousal theory is only supported by weak evidence, so the connection between extraversion and cortical arousal is not clear [14]. This means that the difference in personality does not mean the difference in the level of arousal. Both introverted learners and extraverted learners may benefit from background music.

\section{HOW TO USE BACKGROUND MUSIC TO MAXIMIZE THE TASK PERFORMANCE}

Through the analysis of three theories of how background music affects learning, the author explains that the effect of background music on task performance cannot be generalized. The effect is varied by the change of arousal and mood, music types and age differences. From the three theories, the author explains that proper arousal positive mood can lead to better cognitive performance, and the distraction caused by high arousal can lead to worse cognitive performance. From the analysis of the types of background music, the author explains that appropriate fast tempo music can bring moderate arousal level; major mode can increase the mood level of learners; over fast tempo music and lyrical music can bring distraction. From the analysis of learners' characteristics, the author explains that older students are more suitable for listening to background music in their studies, and personality differences have nothing to do with the impact. Summarizing these theories together the conclusion is that listening to appropriate fast-major music with no lyrics can maximize task performance, especially older students can achieve better performance. 


\section{CONCLUSION}

In general, this paper systematically discusses previous research on background music, and reviews three theories of how background music affects learning. The Mozart effect refers to the positive influence of Mozart's music on spatial ability. Then this paper uses the arousal and mood hypothesis to explain the Mozart effect, showing that background music indirectly affects cognitive performance through arousal and mood. And then this paper proposes the Seductive detail effect, which has an opposite attitude to the previous two theories. The Seductive detail effect indicates that background music brings extraneous cognitive load which distracts learners. The author also discusses the differences in the types of background music and learners' personal characteristics that change the impact of background music on task performance. Fast tempo music and major mode have a positive effect on learning, while slow tempo music and minor mode have a negative effect. Non-lyrical music and silence bring better learning results than lyrical music. Older students are more aware of the negative effects of background music on learning and are willing to make changes to reduce the negative effects. Therefore, if young people (especially older students) want to achieve better task performance, choosing appropriate fast-major music with no lyrics is the best choice.

In further research, researchers can consider applying background music to the field of education, such as playing appropriate background music in the classroom to stimulate students' cognitive functions. However, the real teaching environment is complex, people may need to consider more extraneous factors and make countermeasures.

\section{ACKNOWLEDGMENT}

I would like to thank my instructor, Han Min for her support and guidance at every stage of my research, and I would like to acknowledge my professor for getting me interest in the study of cognitive psychology.

Finally, I would like to thank my parents for their support and encouragement for my research program.

\section{REFERENCE}

[1] Mohan, A., \& Thomas, E. (2020). Effect of background music and the cultural preference to music on adolescents' task performance. International Journal of Adolescence \& Youth, 25(1), 562-573.

[2] Lehmann, J., \& Seufert, T. (2017). The Influence of Background Music on Learning in the Light of Different Theoretical Perspectives and the Role of
Working Memory Capacity. Frontiers in psychology, 8, 1902-1902.

[3] Rauscher, F., Shaw, G., \& Ky, K. (1993). Music and spatial task performance. Nature (London), 365(6447), 611-611.

[4] Perham, N., \& Withey, T. (2012) Liked Music Increases Spatial Rotation Performance Regardless of Tempo. Current Psychology, 31(2), 168-181.

[5] Perham, N., \& Currie, H. (2014). Does listening to preferred music improve reading comprehension performance? Applied

Cognitive Psychology, 28(2), 279-284.

[6] Husain, G., Thompson, W., \& Schellenberg, E. (2002). Effects of Musical Tempo and Mode on Arousal, Mood, and Spatial Abilities. Music Perception, 20(2), 151-171.

[7] Thompson, W., Schellenberg, E., \& Husain, G. (2001). Arousal, Mood, and the Mozart Effect. Psychological Science, 12(3), 248-251.

[8] Pekrun, R., Lichtenfeld, S., Marsh, H., Murayama, K., \& Goetz, T. (2017). Achievement Emotions and Academic Performance: Longitudinal Models of Reciprocal Effects. Child Development, 88(5), 1653-1670.

[9] He, W., Wong, W., \& Hui, A. (2017). Emotional Reactions Mediate the Effect of Music Listening on Creative Thinking: Perspective of the Arousal-and-Mood Hypothesis. Frontiers in Psychology, 8, 1680-1680.

[10] Garner, R., Gillingham, M., \& White, C. (1989). Effects of 'Seductive Details' on Macroprocessing and Microprocessing in Adults and Children. Cognition and Instruction, 6(1), 41-57.

[11] Park, B., Moreno, R., Seufert, T., \& Brünken, R. (2011). Does cognitive load moderate the seductive details effect? A multimedia study. Computers in Human Behavior, 27(1), 5-10.

[12] Kotsopoulou, A., \& Hallam, S. (2010). The perceived impact of playing music while studying: age and cultural differences. Educational Studies, 36(4), 431-440.

[13] Eysenck H. (1967). The Biological Basis of Personality. Springfield, Ill: Thomas.

[14] Küssner M. (2017). Eysenck's Theory of Personality and the Role of Background Music in Cognitive Task Performance: A Mini-Review of Conflicting Findings and a New Perspective. Frontiers in psychology, 8, 1991-1991. 